\title{
Use of cement-fly ash-based stabilization techniques for the treatment of waste containing aromatic contaminants
}

\author{
Kamil Banaszkiewicz ${ }^{1, *}$, and Tadeusz Marcinkowski ${ }^{1}$ \\ ${ }^{1}$ Wroclaw University of Science and Technology, Faculty of Environmental Engineering, Wybrzeze \\ Wyspianskiego 27, 30-370 Wroclaw, Poland
}

\begin{abstract}
Research on evaluation of evaporation rate of volatile organic compounds from soil beds during processing is presented. For the experiment, soil samples were prepared with the same amounts of benzene and stabilized using a mixture of CEMI 42.5R cement and fly ash from pit-coal combustion. Solidification of soils contaminated with BTEX hydrocarbons using hydraulic binders involves a risk of releasing vapours of these compounds during homogenization of waste with stabilizing mixture introduced and its dilution with water. The primary purposes of the research were: analysis of benzene volume emitted from soil during stabilization/solidification process and characterization of factors that may negatively affect the quality of measurements/the course of stabilization process. Analysis of benzene emission intensity during the process was based on concentration $\left(\mathrm{C}_{6} \mathrm{H}_{6}\right)$ values, recorded with flame-ionization detector above the surface of reacting mixture. At the same time, gaseous contaminants emitted during waste stabilization were passed through pipes filled with activated carbon (SCK, Anasorb CSC). Benzene vapours adsorbed on activated carbon were subjected to analysis using gas chromatograph Varian 450-GC. Evaporation characteristics of benzene during processing contaminated soils revealed the stages creating the highest danger to workers' health, as well as a need for actions connected with modification of technological line.
\end{abstract}

\section{Introduction}

The main cause of soil degradation are chemical contaminants emerging as a result of human activity - their composition and volume are beyond possibilities of their treatment by the natural environment. Organic compounds introduced to soil, depending on the kind of ground, may occur in the following forms: gaseous - dispersed in pores or adsorbed on soil particles; liquid - immiscible with water or dissolved in water; or solid. As a result of migration they can cause pollution of significant areas of pedosphere, as well as surface and ground water.

* Corresponding author: kamil.banaszkiewicz@pwr.edu.pl 
Aromatic hydrocarbons belong to main pollutants of soil and ground water occurring in the vicinity of oil deposits, petroleum gas producing plants and storage areas for gasolines and other petroleum-derived substances. Due to toxic, mutagenic or cancerogenic properties of organic solvents even their small amounts in water or soil creates a serious risk to human health and requires instantaneous actions to reduce their propagation and remove such substances from the natural environment.

Benzene is used in numerous processes as solvent or base material for further synthesis. It has common applications in such branches as rubber industry, pharmaceutical industry and paints, lacquers and plastics industry [1]. Overall benzene production in EU is estimated at about 7 million tonnes annually [2] Due to its high volatility, ability to create high concentrations in air, inflammability and carcinogenicity, all processes with large evaporation area and little chance of hermetization are highly dangerous.

Remediation of contaminated area, i.e. cleaning and removing contaminants emerged as a result of routine industrial activities or unexpected failure may be performed by elimination, decomposition, immobilization or chemical transformation into less toxic, less mobile and less reactive forms. The choice of method of cleaning/neutralizating contaminated soil depends on volume and physico-chemical properties of introduced pollutants, as well as on geohydrologic conditions [3].

One of the technologies widely used for immobilizing inorganic and (not so often) organic constituents of hazardous waste is stabilization/solidification $(\mathrm{S} / \mathrm{S})$ process using hydraulic binders. S/S of contaminated soil may be performed in situ - in the place where pollution occurred, or ex situ, e.g. in a waste processing plant [4]. Reduction of organic and inorganic pollutants mobility is a result of the reactions of precipitation, hydrolysis, oxidation/reduction, complexation or adsorption [5, 6]. Significant impact of organic pollutants on cement hydration process restricts possibilities of $\mathrm{S} / \mathrm{S}$ technology [6], therefore the efficiency of immobilization of organic contaminants in cement depends strongly on possibilities of their physical lock-up [7]. Additionally, in order to reduce the impact of organic pollutants on the course of S/S process, various cement additives are applied, such as: fly ash, powdery clays, quick lime, hydrated lime, gypsum and natural resins.

The effect of organic substances on slower fixation and hardening of cement was observed e.g. during mixing cement with water, methanol and 2-monochloroaniline, in volumetric proportions of 100/76/4 [8]. Basic cement reactions remained the same, but they were running slower. For example, Gussoni et al. [9], on the basis of their research using magnetic resonance techniques, report formation of big pockets containing liquids during the first hours and days of hydration in presence of methanol and dichloroaniline. Using X-ray diffractometry, the same authors showed that a solution containing the two compounds mentioned retains its ability to slow-down hydration even after 6 months of maturation of examined material [9]. Vipulanandan [10] reports that the presence of phenol in amount of $10 \%$ causes about sevenfold elongation of total time of cement solidification.

Despite significant limitations in application of cement for stabilization of wastes containing hydrocarbons, such applications are in use and we have relations [11], according to which it is possible to solidify properly wastes containing some polycyclic aromatic hydrocarbons. Indeed, particles of polycyclic aromatic hydrocarbons cannot be built into the cement matrix, but still their physical encapsulation is possible to some extent [12]. $\mathrm{S} / \mathrm{S}$ with cement was also proposed as a method of processing waste (e.g. sludges from petrochemical industry), containing non-polar organic compounds, such as aromatic hydrocarbons, halogenated hydrocarbons and polychlorinated biphenyls, that is feasible on specific conditions [13].

Experimental data on parameters of leaching hydrocarbons from petroleum refinery sludges stabilized/solidified with various amounts of cement are scarce and concern only 
the Trzebinia Refinery and the Czechowice-Dziedzice Refinery. S/S with cement and similar materials should be recognized as a technology that is economically justified and can be implemented in a relatively short time - it was confirmed in some Polish petroleum refineries.

Solidification of waste with hydraulic binders requires its mechanical mixing in order to disperse in the entire volume of waste and to dilute with water. This is a process during which (in case of processing waste contaminated with aromatic hydrocarbons) poses a risk of releasing vapours of volatile organic compounds. This concerns mainly the stage of material homogenization and initiation of hydration process with dilute water. The primary purposes of the research were: (a) analysis of benzene volume emitted from soil during $\mathrm{S} / \mathrm{S}$ process (based on continuous measurements of concentrations of gaseous contaminants above the surface of reacting mixture), (b) verification of continuous measurements on the basis of chromatographic analysis of benzene vapours adsorbed on activated carbon, (c) characterization of factors that may negatively affect the quality of measurements/the course of stabilization process.

\section{Materials and methodology}

\subsection{Soil samples and binders}

Soil bed used in the research was poorly coherent and was characterized by hydration at the level of $\mathrm{W}=3.41 \%$, and low content of organic substances $(1.97 \%$ d.m. $)$. As a result of low cohesion, the material had a high permeability. The structure of used soil allowed easy dispersion of binding materials in entire volume, but at the same time created a risk of significant emission of gaseous pollutants from intergranular spaces.

In the experiment a sample of $200 \mathrm{~g}$ soil was weighted, put into a container and contaminated with benzene (p.a.grade, Chempur) in amount of $0.5 \mathrm{~mL}$. Then containers with samples were shut close, to reduce evaporation of gaseous contaminants. In order to distribute solvent in entire volume of material, tightly closed samples were placed in somersault shaker (Heidolph Reax 20/8). Time of mixing was 120 s. Prepared samples were stored for $24 \mathrm{~h}$ in the temperature of about $7^{\circ} \mathrm{C}$.

Soil contaminated with benzene was processed with a mixture of cement and fly ash from pit-coal combustion. The content of each component in binding mixture amounted to $70 \%$ and $30 \%$, respectively. Cement used in the experiment was up to PN-EN 197-1 standard, had a durability class of 42.5 and a high early strength: CEM I $42.5 \mathrm{R}$. This material does not contain any mineral additives, $95-100 \%$ of its mass is clinker, $0-5 \%$ secondary components (inorganic materials from clinker manufacturing). The main minerals of Portland clinker are di- and tricalcium silicates (alite and belite) that together constitute $74 \%$ of its mass $[14,15]$ Portland cement CEM I $42.5 \mathrm{R}$ is a binder characterized by large amounts of heat released during hardening, as well as high rate of its releasing. In case of solidifying soils contaminated with organic solvents, higher temperature of hydration (apart from the risk of microfractures when the limit value is exceeded) [16], may cause increase in volatile contaminants emissions [17].

Additional component used in research was fly ash from pit-coal combustion. Introduction of this material leads to extended time of mixture fixation, as well as decrease in its specific density. As a result, application of cement and fly ash mixture in the same amount as Portland cement CEM I alone leads to introduction of greater volume of binding material and therefore to a final product characterized by lower permeability [16]. Addition of fly ash, parallel to reduction of cement content, causes decreased contraction shrinkage of mixture. 
When replacing a part of cement with fly ash also the content of non-burnt coal (roasting loss) should be concerned. Coal increases water absorbance of ash and as a result may have adverse impact on hardiness of a product containing cement-fly-ash mixture. Due to spherical shape of grains, siliceous fly ash considerably improves workability, tightness and strength of a concrete [18-20]. Ashes used in reported research were characterized by roasting loss at the level below $5 \%$.

\subsection{Measuring equipment for volatile organic compound}

Continuous measurements of concentrations of benzene emitted from reacting mixture during the solidification process were performed using the MicroFID flame-ionization detector (Photovac). The concentration meter was calibrated for methane, whereas concentrations measured were converted into volume of benzene in the air. The volume of sample taken by the instrument $0.6 \mathrm{~L} / \mathrm{min}$, benzene concentration was recorded in 5 seconds intervals.

At the same time, gaseous contaminants emitted during waste stabilization were passed through pipes filled with activated carbon (SCK, Anasorb CSC), using two-channel aspirators LAT ASP - 3 II. Rate of flow was ca. $60 \mathrm{~L} / \mathrm{h}$, corresponding to the volume of 4.7 to $5.1 \mathrm{~L}$ of process gases, aspired to activated carbon bed in particular phases of process.

Vapours of volatile organic compounds adsorbed on activated carbon were subjected to concentrations analysis using gas chromatograph Varian 450-GC and columns Varian VF-WAXms (30 m x $0.25 \mathrm{~mm}$ ID DF: $0.25 \mu \mathrm{m}$ ). In order to do that, activated carbon from absorbing pipe was put into $5 \mathrm{~cm}^{3}$ flasks, then $2 \mathrm{~mL}$ of carbon disulphide $\left(\mathrm{CS}_{2}\right)$ was added. Flasks were shut close and left for $20 \mathrm{~min}$., with their content shaken from time to time. Then the solution from above the carbon layer was taken into $2 \mathrm{~mL}$ vial and placed in autosampler of chromatograph. Desorption coefficient of the method was $80 \%$.

Tests were performed in the following conditions: the temperature of furnace (column) $-110^{\circ} \mathrm{C}$ for $10 \mathrm{~min}$; ; temperature of batchmeter $-225^{\circ} \mathrm{C}$; split $-1 / 20$, temperature of detector $-250^{\circ} \mathrm{C}$; carrier gas - helium; flow rate of carrier gas $-1 \mathrm{~mL} / \mathrm{min}$; volume of injection $-5 \mu \mathrm{L}$.

\subsection{Methodology of the stabilization/solidification process}

$\mathrm{S} / \mathrm{S}$ of soil contaminated with benzene was performed in a reactor for cement mortars Tecnotest B205/X5. Air samples from above the reacting mixture were taken through teflon pipes introduced into the reactor bowl. All channels ended on the same depth, about $2 \mathrm{~cm}$ below the rim of the bowl. Pipes with activated carbon were mounted on two channels, the third one was connected directly with the flame-ionization detector (VOC measuring equipment). S/S process was performed in two stages: (1) waste homogenization phase homogenizing the mixture of waste and the binding blend. (2) hydration phase - initiation of fixation process in binders through introducing diluent water. The amount of water was determined on the basis of research on workability of mixtures containing stabilizing agents and contaminated soil.

The whole process lasted for 10 minutes, 300 seconds each of phases. Detailed material composition of solidified waste samples is presented in Table 1. Every time before the start of test series the ambient temperature and humidity were measured using Hanna Instruments HI 9564 thermo-hygrometer. After each gas sampling all ducts were washed with clean air in order to remove residues of gases and dusts accumulated in ducts. Measuring series started with background measurement (about $60 \mathrm{~s}$ ) and then concentrations in teflon ducts with the aim of verifying purity of air and possible additional 
cleansing of ducts. In order to reduce influence of external factors on gaseous contaminants emission, all materials (binders and waste) were mixed with a constant speed (planetary speed $62 \mathrm{rpm}$ (clockwise); beater speed $140 \mathrm{rpm}$ (anticlockwise)).

Table 1. Material composition of composites produced from soil contaminated with benzene, as well as ambient conditions (humidity and temperature).

\begin{tabular}{|c|c|c|c|c|c|c|}
\hline Sample & Soil & Benzene & $\begin{array}{c}\text { Portland } \\
\text { cement }\end{array}$ & Fly ash & Temperature & Humidity \\
\hline Sample 0 & $200 \mathrm{~g}$ & $0.5 \mathrm{~mL}$ & $0 \mathrm{~g}$ & $0 \mathrm{~g}$ & $20.1 \pm 0.5^{\circ} \mathrm{C}$ & $25.4 \pm 3 \% \mathrm{RH}$ \\
\hline Sample 80 & $200 \mathrm{~g}$ & $0.5 \mathrm{~mL}$ & $56 \mathrm{~g}$ & $24 \mathrm{~g}$ & $20.1 \pm 0.5^{\circ} \mathrm{C}$ & $25.4 \pm 3 \% \mathrm{RH}$ \\
\hline Sample 120 & $200 \mathrm{~g}$ & $0.5 \mathrm{~mL}$ & $84 \mathrm{~g}$ & $36 \mathrm{~g}$ & $20.1 \pm 0.5^{\circ} \mathrm{C}$ & $25.4 \pm 3 \% \mathrm{RH}$ \\
\hline Sample 160 & $200 \mathrm{~g}$ & $0.5 \mathrm{~mL}$ & $112 \mathrm{~g}$ & $48 \mathrm{~g}$ & $20.1 \pm 0.5^{\circ} \mathrm{C}$ & $25.4 \pm 3 \% \mathrm{RH}$ \\
\hline
\end{tabular}

\section{Discussion and results}

Every process of neutralization of waste contaminated with volatile organic compounds is characterized by technical parameters that may determine their emissions during processing. In case of $\mathrm{S} / \mathrm{S}$ processes, as actions causing release of volatile or semi-volatile compounds we can count: (1) mixing waste with binding components, (2) diluting mixture with water that can displace volatile organic compounds from adsorption places, (3) increase in temperature of reacting mixture during hydration of binding factors (e.g. mixture of cement and lime) [5]. Knowledge of characteristics of gaseous contaminants emission enables evaluation of the process dynamics, as well as effectiveness of actions that stabilize releasing vapours of volatile organic compounds.

The total volume of benzene emitted in the first phase was a few dozen times greater than in the phase of hydration (Table 2). Results of continuous measurements confirmed that the course of emission of the solvent analyzed was very dynamic. The highest momentary concentration of benzene in the reactor (in all tests, irrespective of binding mixture dose) was recorded in the first $40 \mathrm{~s}$ of the process. Intensity of releasing benzene vapours might me closely related to mixing of contaminated soil. Applied rotary speed $140 \mathrm{rpm}$ (suggested by the manufacturer of universal planetary mixer for asphalt and cement) might be too high for material contaminated with volatile organic compounds. Application of lower speed might have a positive effect and reduce a sudden emission.

Table 2. Amount of benzene adsorbed on activated carbon (GC analysis).

\begin{tabular}{|c|c|c|c|c|}
\hline $\begin{array}{c}\text { Phase of } \\
\text { process }\end{array}$ & Sample 0 & Sample 80 & Sample 120 & Sample 160 \\
\hline $\begin{array}{c}\text { Homogeniza } \\
\text { tion phase }\end{array}$ & $65 \mathrm{mg}$ & $49 \mathrm{mg}$ & $41 \mathrm{mg}$ & $37 \mathrm{mg}$ \\
\hline $\begin{array}{c}\text { Hydration } \\
\text { phase }\end{array}$ & $\begin{array}{c}\text { not } \\
\text { measured }\end{array}$ & $1.02 \mathrm{mg}$ & $0.71 \mathrm{mg}$ & $0.78 \mathrm{mg}$ \\
\hline
\end{tabular}

Besides, a significant emission of dusts from binders was observed during homogenization of soil with binding components (the $1^{\text {st }}$ phase of the process). Emitted solid pollutants were sucked in together with air from the reactor bowl. A considerable part of dusts settled on walls of ducts and was captured on a filter before combustion chamber of the MicroFID detector. In order to reduce effect of pollination on the quality of measurements, each time the ducts were blown through with clean air. Also in this case reduction of mixer speed might prove positive. 
The research confirmed positive impact of hermetization of waste using cement-ash mixture. Along with increased dose of binding components, a decrease in benzene concentration in reactor was observed. In case of the sample 160 during the phase of homogenization, the amount of solvent adsorbed on activated carbon was lower by $43 \%$ (Fig. 1). For the sample solidified with the lowest amount of mixture $(80 \mathrm{~g})$ the emission was lower by $24 \%$. A reduction of benzene vapours mobility in the first phase of process did not cause its increase in the phase of diluting mixture with water. The average concentrations of benzene in the second phase of process were 190 to $270 \mathrm{mgC}_{6} \mathrm{H}_{6} / \mathrm{m}^{3}$. For the samples 120 and 160 the amount of volatile organic compounds above the surface of mixture were comparable and amounted to 190 and $196 \mathrm{mgC}_{6} \mathrm{H}_{6} / \mathrm{m}^{3}$, respectively.

For continuous measurements a similar characteristics of changes was observed. A decrease in total amount of released benzene, along with an increase in stabilizing mixture mass was 19, 25 and 35\%, respectively (Fig. 1).
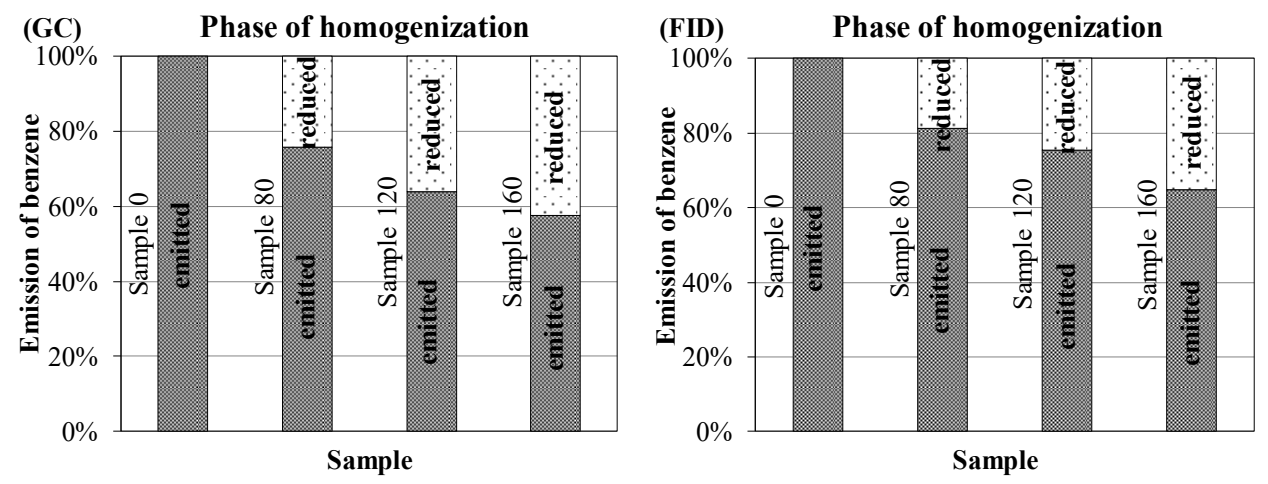

Fig. 1. Reduction of the total benzene emission during the process of S/S - GC/FID.

Evaporation characteristics of benzene in processing contaminated soils did not show a significant effect of binding mixture dose on dynamics of benzene vapors releasing during the phase of homogenization (Fig. 2). As a result of introduction of hydraulic binders a decrease was observed in maximum momentary benzene concentration by: 19, 24 and $43 \%$. Suppression of sudden evaporation was a result of (among others) sealing the soil with fine (powdery) binding materials. One of the components of binding mixture was fly ash that is characterized with greater specific area, compared with cement.
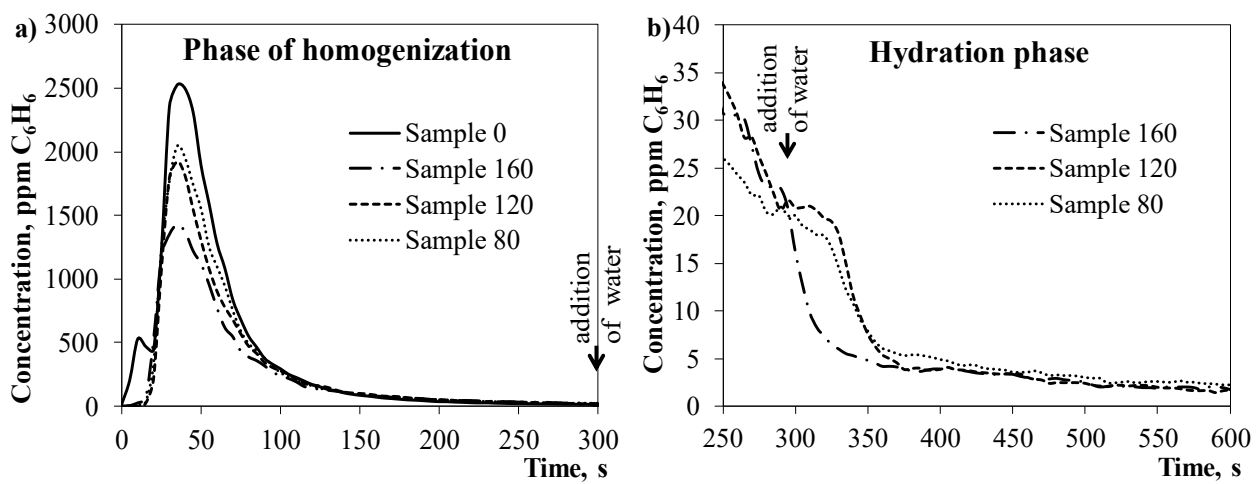

Fig. 2. Amount of benzene emission during the S/S process: a) homogenization phase, b) phase of hydration. 
Another neuralgic phase of the S/S process is the stage of hydration. In order to initialize concretion of hydraulic binders, introduction of diluent water is necessary. The dose of water is closely connected with the amount of cement used, as well as with water absorption capability of mineral additives (e.g. fly ash) and soil being neutralized. In case of neutralizing soils contaminated with volatile organic compounds, suppression of their emission in the phase of homogenization through sealing soil with binding mixture may cause releasing of greater amounts during hydration.

According to the process methodology, water was introduced in $300 \mathrm{~s}$. In case of sampled being solidified with cement-ash mixture in amount of 80 and $120 \mathrm{~g}$ a phenomenon of displacing benzene vapours adsorbed in micro/macropores by water was observed (on-line measurements) (Fig. 2).

Total amount of released benzene calculated on the basis of momentary concentration measurements in hydration phase did not correspond to the mass adsorbed on activated carbon (Fig. 3). Inconsistencies concerned a sample solidified with a dose of $120 \mathrm{~g}$ binding mixture. In case of continuous measurements benzene emissions in hydration phase for the samples 120 and 80 were very similar (Fig. 3).
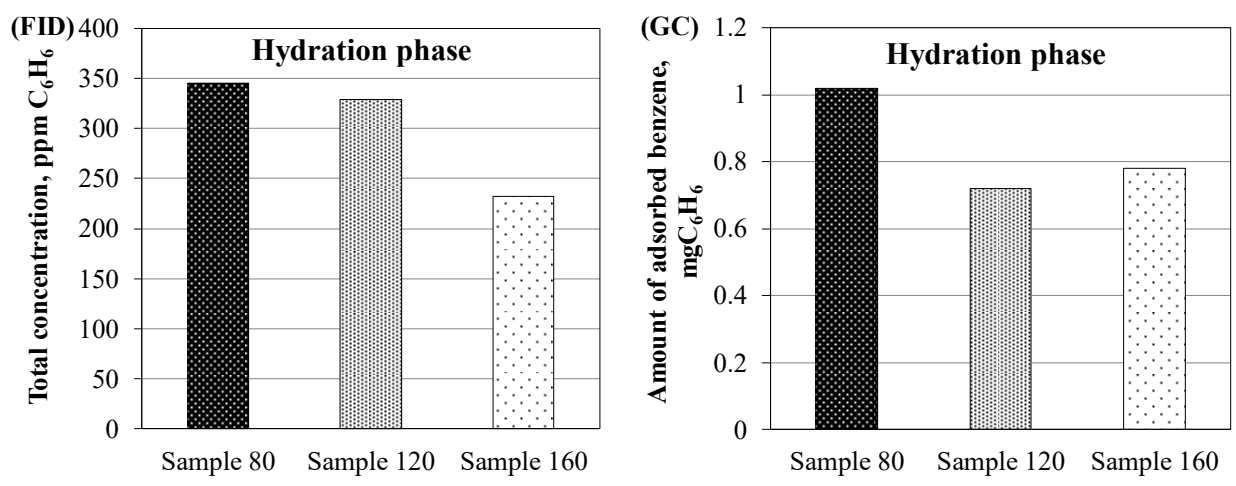

Fig. 3. Total amount of gaseous contaminants: released in the course of S/S process (FID), adsorbed on activated carbon in the phase of hydration (GC).

The amount of benzene fixed on the surface of activated carbon in the second phase of process for the samples 120 and 160 was 0.71 and $0.78 \mathrm{mg}$, respectively. Recorded variations may be a result of measurement error caused by clogging the sucking ducts by solid particles (dusts). Besides, differences in flow rates of process gases sucked in by measurement equipment also should be concerned. The volume of air sample taken into flame-ionization detector was $0.6 \mathrm{~L} / \mathrm{min}$. A flow rate of air passing through pipes with activated carbon (SCK, Anasorb CSC) was about $1 \mathrm{~L} / \mathrm{min}$. Total volumes of analyzed air inside the reactor were: ca. 4.7-5.1 L (GC), ca. 3 L (FID).

\section{Conclusions}

Choice of the remediation method is determined mostly by a kind of contaminants and their concentration. Reported method may be effective in case of application for soils contaminated at the same time with mineral and organic compounds, and as a technique supporting another process of remediation. In reported research the greatest extent of reduction of benzene emission was achieved in the sample 160, in which a binding mixture made $80 \%$ of the mass of soil being neutralized. Large dose of stabilizing components causes increase of mass/volume of waste. The content of cement if obtained composites may be lowered by application of additional components sorbing organic contaminants, e.g. 
activated carbon, powdery clay or rubber. Also micro-aggregates should be taken into account in choice of composition of stabilizing mixtures.

The essential factor affecting the quality of measurements are dusts from fine-grained binders. Intensity of dusting may be controlled through lowered rotary speed of a mixer, which in turn will prolong the time of homogenizing and diluting mixture. Large amounts of solid contaminants cause occlusion of dust-filters.

\section{References}

1. A. Kalina, Principles and methods of assessing the working environment 2000, 16, 3 , 149-158 (2000) (in Polish)

2. P. Stepnowski, E. Synak, B. Szafranek, Z. Kaczyński, Monitoring and analytics of pollutants in the environment (The University of Gdańsk Press, 2010) (in Polish)

3. K. Radwan, Z. Ślosorz, J. Rakowska, Safety \& Fire Technique 3, 107-114 (2012) (in Polish)

4. U.S. EPA: Treatment Technologies for Site Cleanup: Annual Status Report (Twelfth Edition), EPA-542-R-07-012 (2007)

5. U.S. EPA/Bone B.D. Review of scientific literature on the use of stabilisation/solidification for the treatment of contaminated soil, solid waste and sludges, Science Report SC980003/SR2 (2004)

6. U.S. EPA, Innovative Site Remediation Design and Application 4, Stabilization/Solidification, EPA 542/B-97/007. Office of Solid Waste and Emergency Response (1997)

7. S. Trussell, R.D. Spence, Waste Manage. 14, 6, 507-519 (1994)

8. N.I. Sora, R. Pelosato, D. Botta, G. Dotelli, J. Eur. Ceram. Soc. 22, 1463-1473 (2002)

9. M. Gussoni, F. Greco, F. Bonazzi, A. Vezzoli, D. Botta, G. Dotelli, I.N. Sora, R. Pelosato, L. Zetta, Magn. Reson. Imag. 22, 877-889 (2004)

10. C. Vipulanandan, S. Krishnan, Cement Concrete Res. 23, 4, 792-802 (1993)

11. V.M. Hebatpuria, H.A. Arafat, H.S. Rho, P.L. Bishop, N.G. Pinto, R.C. Buchanan, J. Hazard. Mater. B 70, 117-138 (1999)

12. E. Mulder, J.P. Brouwer, J. Blaakmeer, J.W. Frenay, Waste Manage. 21, 247-253 (2001)

13. M.D. LaGrega, P.L. Buckingham, J.C. Evans, Hazardous Waste Management (McGraw-Hill, New York, NY, 1994)

14. W. Kurdowski, Cement chemistry (Polish Scientific Publishers PWN, Warszawa, 1991) (in Polish)

15. W. Kurdowski, Chemistry of building materials (AGH University of Science and Technology Press, Kraków, 2003) (in Polish)

16. Z. Giergiczny, Cement, aggregates, concrete in offer of Górażdże Group. Types, properties, application (Chorula, 2011) (in Polish)

17. U.S. EPA, In Situ Treatment Technologies for Contaminated Soil, EPA 542/F-06/013, (2006)

18. J. Jasiczak, P. Mikołajczak, Technology of concrete modified with admixtures and additives (Poznan University of Technology, Alma Mater, 2003) (in Polish)

19. J. Newman, B.S. Choo, Advanced Concrete Technology (Elsevier Ltd., 2003)

20. H.F.W. Taylor, Cement chemistry (ACADEMIC PRESS, London, 1990) 